\title{
Primary hyperparathyroidism and incidental multifocal metastatic papillary thyroid carcinoma in a man
}

\author{
Hiperparatiroidismo primário e carcinoma papilífero metastático, \\ multifocal e incidental da tiroide em paciente do sexo masculino
}

Stergios A. Polyzos' ${ }^{1}$, Athanasios D. Anastasilakis², loannis P. lakovou ${ }^{3}$, Valassia Partsalidou ${ }^{4}$

1 Second Medical Clinic, Medical School, Aristotle University of Thessaloniki, Ippokration Hospital, Thessaloniki, Greece ${ }^{2}$ Department of Endocrinology, 424 Military Hospital, Thessaloniki, Greece ${ }^{3}$ Third Department of Nuclear Medicine, Medical School, Aristotle University of Thessaloniki, Papageorgiou Hospital, Thessaloniki, Greece ${ }^{4}$ Department of Pathology, Papanikolaou Hospital, Thessaloniki, Greece

Correspondence to: Stergios A. Polyzos, Endocrinologist 13 Simou Lianidi str. 55134 - Thessaloniki, Greece stergios@endo.gr

\section{SUMMARY}

Co-existence of primary hyperparathyroidism (PHPT) and non-medullary thyroid carcinoma has been previously reported in sporadic case reports and some surgical series, but the majority of cases concerned women with occult papillary carcinomas without cervical lymph node involvement. We present a 71-year man with PHPT and multinodular goiter who was subjected to surgery for single parathyroid adenoma and was found to have synchronous multifocal papillary thyroid carcinoma (PTC) with cervical lymph node involvement. Review of the literature retrieved only a few similar cases. Ultrasonography of both thyroid and parathyroid glands might be considered in patients with hyperparathyroidism. Given that there are no specific guidelines for the management of patients with synchronous PHPT and PTC, they should be managed like the cases of single PTC. Arq Bras Endocrinol Metab. 2010;54(6):578-82

\section{SUMÁRIO}

A coexistência de hiperparatiroidismo primário (HPTP) e de carcinoma da tiroide não medular foi descrita anteriormente em relatos de caso esporádicos e em algumas séries cirúrgicas. Entretanto, a maioria dos casos se referiu a mulheres com carcinoma papilífero oculto sem o comprometimento de linfonodos cervicais. Apresentamos um paciente de 71 anos de idade do sexo masculino com HPTP e bócio multinodular que foi submetido a uma cirurgia para adenoma solitário da paratiroide e foi encontrado carcinoma papilífero da tiroide (PTC) multifocal com comprometimento de linfonodos cervicais. Uma revisão da literatura resultou em apenas alguns casos similares. A realização de uma ultrassonografia das glândulas tiroide e paratiroide pode ser considerada em pacientes com hiperparatiroidismo. Como não existe diretriz específica para o tratamento de pacientes com concomitância de HPTP e PTC, eles devem ser tratados como um caso isolado de PTC. Arq Bras Endocrinol Metab. 2010;54(6):578-82

\section{INTRODUCTION}

$\mathrm{P}$ rimary hyperparathyroidism (PHPT) is the third most common endocrine disorder and a single gland adenoma is accounting for $75 \%-85 \%$ of the cases ( 1 ). The incidence of PHPT is currently $27-30$ per 100,000 person-years; it is twice as high in women and increases with age. Asymptomatic disease is common. The treatment of choice for PHPT is surgical removal of the hyperfunctioning tissue. Experienced surgeons are estimated to identify an affected gland in $95 \%$ of cases (1). However, there is still controversy about the first option therapy for PHPT, especially in asymptomatic patients older than 50 years $(1,2)$.

Papillary thyroid carcinoma (PTC) is the most common malignant tumor of the thyroid. It usually presents as a solitary or dominant nodule, but multifocality is not uncommon (3). The incidence of PTC (currently 7.7 per 100,000 person-years in the United States) is higher in women and is rising, predominantly due to the increased detection of occult papillary carcinomas, which have negligible impact on overall mortality $(4,5)$. Total thyroidectomy, which may be followed by ablation with 
radioactive iodine, is the recommended management for PTC and the prognosis is usually favorable (6).

Co-existence of PHPT and non-medullary thyroid carcinoma (NMTC) has been previously reported in case reports and some surgical series. In large series, NMTC was reported to be between $2.1 \%$ and $4.3 \%$ in patients subjected to surgery for PHPT (7-13). The majority of the cases were women with unifocal occult PTC without cervical lymph node involvement; many of them were associated with previous head and neck irradiation.

We present hereby a man with PHPT due to a single parathyroid adenoma and multinodular goiter, who was subjected to surgery and was found to have synchronous bilateral multifocal PTC with cervical lymph node involvement.

\section{CASE REPORT}

A 71-year-old asymptomatic man presented to our clinic (October 2008) for mild biochemical hypercalcemia (serum calcium $10.8 \mathrm{mg} / \mathrm{dL}$, reference range 8.1-10.4 $\mathrm{mg} / \mathrm{dL}$ ) incidentally found on routine check-up. He had had essential hypertension since 1992, hyperlipidemia since 2002 and atrial fibrillation since 2005 . At presentation, he was receiving amlodipine $5 \mathrm{mg}$, celiprolol hydrochloride $200 \mathrm{mg}$ and atorvastatin 10 $\mathrm{mg}$ once daily. The patient reported no history of head or neck irradiation or a neck mass. Clinical examination was unremarkable. Blood tests revealed mildly elevated serum total calcium $(10.6 \mathrm{mg} / \mathrm{dL})$, low-normal phosphate $2.5 \mathrm{mg} / \mathrm{dL}$ (reference range $2.5-4.5 \mathrm{mg} /$ $\mathrm{dL}$ ) and increased serum intact parathyroid hormone (PTH) $(202 \mathrm{pg} / \mathrm{mL}$, reference range $7-53 \mathrm{pg} / \mathrm{mL})$, findings suggestive for PHPT. The patient had normal 24-hour urinary calcium excretion $(251 \mathrm{mg} /$ day, reference range $100-300 \mathrm{mg} /$ day) and 24-hour urinary total metanefrines $(55 \mu \mathrm{g} /$ day, normal $<600 \mu \mathrm{g} /$ day $)$. Serum thyroid-stimulating hormone (TSH), free thyroxine (FT4) and calcitonin were normal $(2.7 \mathrm{IU} / \mathrm{L}$, $1.4 \mathrm{ng} / \mathrm{dL}$ and $1 \mathrm{pg} / \mathrm{mL}$, respectively; reference ranges 0.4-4.0 IU/L, 0.8-1.9 ng/dL and 0-10 pg/mL, respectively). Serum kidney and liver function tests were normal, as well as creatinine clearance.

Two phase Technetium ( $\left.{ }^{99 \mathrm{~m}} \mathrm{Tc}\right)$-Sestamibi scintigraphy revealed an area of increased radioactivity at the inferior pole of the left thyroid lobe, which was suggestive of a parathyroid adenoma (Figure 1). Ultrasonography of the neck revealed a potential $1-\mathrm{cm}$ parathyroid ad- enoma at the inferior pole of the left thyroid lobe and a multinodular goiter. Three thyroid nodules had maximum diameter over $1 \mathrm{~cm}$. Two of them were hypoechoic. The dominant nodule was in the right thyroid lobe; it had microcalcifications and its maximum diameter was $1.5 \mathrm{~cm}$. Nodules were clinically impalpable, possibly because the patient's neck was short and thick.

The patient was subjected to uncomplicated parathyroidectomy of his left inferior parathyroid gland and synchronous total thyroidectomy. No suspicious cervical lymph nodes were found during intraoperative exploration. PTH was normalized postoperatively and remains normal 15 months later. However, serum calcium fell below normal $(7.7 \mathrm{mg} / \mathrm{dL})$ at the third postoperative day and the patient was placed on tablets of calcium carbonate $(1,500 \mathrm{mg})$ and capsules of alphacalcidol ( $1 \mu \mathrm{g})$, which were received orally every day; normocalcemia was restored soon after treatment. Calcium carbonate was discontinued two months later, but repeated efforts to discontinue alphacalcidol resulted in mild hypocalcemia and the patient continues receiving it to sustain serum calcium at low normal levels.

Pathology examination revealed a parathyroid adenoma (left) of maximum diameter $1.5 \mathrm{~cm}$ (Figure 2a) and a small normal parathyroid gland inside the right lobe of the thyroid (Figure 2b). Interestingly, there were three small lymph nodes within the fatty tissue around the parathyroid adenoma, one of which was incidentally found to contain metastatic PTC (Figure 2c). Furthermore, bilateral, multifocal PTC of both classical and follicular variants was found with focal infiltration of fatty tissue around the right lobe of the thyroid.

Three months later (March 2009) the patient received radioiodine ablation dose of $100 \mathrm{mCi}^{131} \mathrm{I}$ followed by suppressive treatment with thyroxine (175 $\mu \mathrm{g} /$ day). Eight months later, in November 2009, a whole

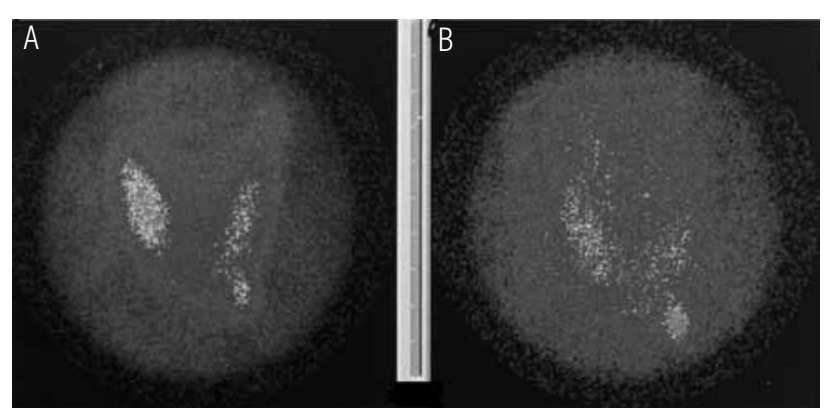

Figure 1. Technetium ( ${ }^{99 \mathrm{~m} T c)}$-Sestamibi scintigraphy revealing an area of increased radioactivity at the inferior pole of the left thyroid lobe suggestive of a parathyroid adenoma; anterior imaging at 20 minutes (A) and 150 minutes (B). 

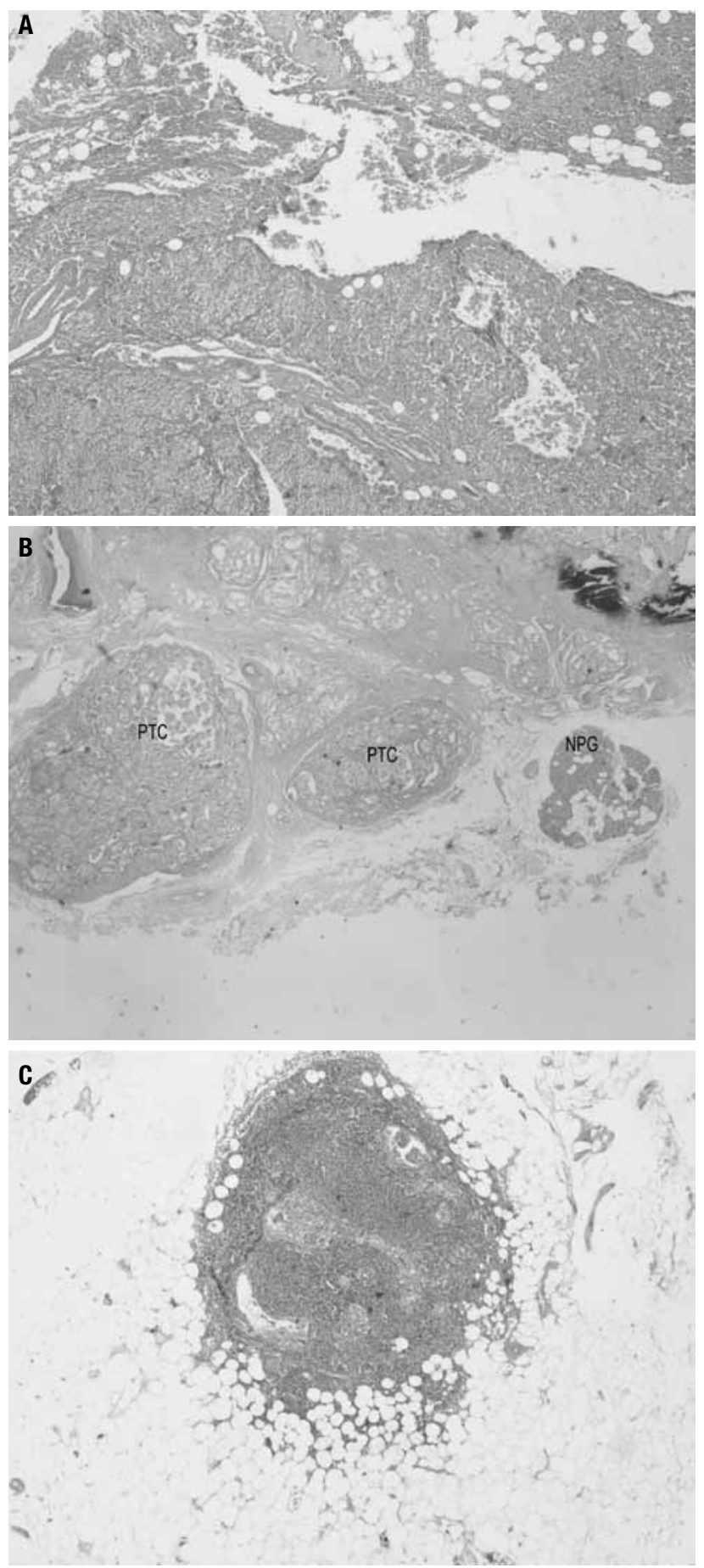

Figure 2. A. Histopathologic section demonstrating typical features of a parathyroid adenoma (left inferior gland; hematoxylin-eosin stain). B. Foci of papillary thyroid carcinoma (PTC) and a normal parathyroid gland (NPG) (right thyroid lobe; hematoxylin-eosin stain). C. A lymph node within the fatty tissue around the parathyroid adenoma (left) incidentally found to contain metastatic papillary thyroid carcinoma.

body diagnostic ${ }^{131} \mathrm{I}$ scintigraphy $(5 \mathrm{mCi})$ after stimulation with recombinant human TSH showed an area of increased uptake at right submandibular region and thyroid bed (Figure 3). Simultaneously measured stimu-

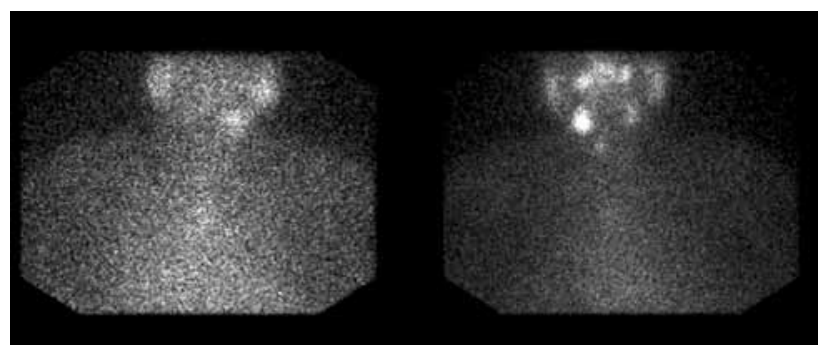

Figure 3. A whole body diagnostic ${ }^{131}$ I scintigraphy ( $5 \mathrm{mCi}$ ) after stimulation with recombinant human TSH showing an area of increased uptake at right submandibular region and thyroid bed.

lated thyroglobulin was $0.9 \mathrm{ng} / \mathrm{mL}$. A neck ultrasonography followed, which showed two potentially metastatic lymph nodes at the right. Subsequently, the patient was subjected to uncomplicated modified radical neck dissection. Twenty-six lymph nodes were dissected; two of them were infiltrated from metastatic PTC and another one had a psammoma body. The patient is currently about to receive a second pulse of radioiodine ablation.

\section{DISCUSSION}

We presented the case of a man with PHPT due to single parathyroid adenoma, who was incidentally found to have concomitant multifocal metastatic PTC. What makes this case exceptional is the extent of thyroid disease, because unifocal occult microcarcinomas were described in most of the previously reported cases.

Based on the incidences of PHPT and PTC $(1,4,5)$, the incidence of co-existence of PHPT and PTC could be roughly estimated to be 0.0023 per 100,000 person-years, if their co-existence is simply attributed to chance. In large surgical series (7-13), NMTC has been reported to be between $2.1 \%$ and $4.3 \%$ in patients subjected to surgery for PHPT. Even higher frequency has been reported in smaller surgical series $(14,15)$. However, given that the variation in frequency depends on the method of examination, patient selection, sample size and surgical procedure, potential selection bias is usually greater by decreasing the sample size. The true incidence of PTC in patients with PHPT is unknown, because: 1) not all patients with PHPT are subjected to surgery; 2) neck exploration is impossible during minimally invasive parathyroidectomy, which becomes more and more popular for patients with PHPT (14).

The association of PHPT and NMTC has elicited speculations for a causative relationship, but the pathogenesis for this concurrence, if any, remains largely unknown. Some authors suggest that it is simple coinci- 
dence with no causal relationship $(7,8)$. It may result from the vicinity of thyroid and parathyroid glands, interpreted in more neck imaging studies due to PHPT and/or exploration of the thyroid during parathyroidectomy. Furthermore, both diseases are predominantly diagnosed in middle-aged women. The high prevalence of occult thyroid carcinoma $(5.3 \%-6.2 \%)$ found in large autopsy studies $(16,17)$ is similar with that found in the above mentioned large surgical series (7-15), which further supports simple coincidence. Finally, PHPT and PTC have different embryologic cell origin (18). On the other hand, other authors suggest previous head and neck irradiation be a common pathogenetic factor for the development of both PHPT and NMTC $(7,11)$, but controversy exists (19). The goitrogenic and carcinogenic effects of calcium and the excessive production of calcitonin in response to hypercalcemia have also been proposed as potential pathogenetic mechanisms (19), but solid evidence is currently lacking; both these hypotheses consider a primary parathyroid abnormality with a secondary effect on the thyroid. A possible common responsible gene and/or growth factors may also play a role $(10,14,19)$, but solid evidence is also lacking.

By reviewing, the above surgical series (7-15) and sporadic case reports $(18,20-22)$, it is observed that: 1) the majority of patients with concurrent PHPT and NMTC are women, possibly due to the increased incidence of both PHPT and PTC in women; 2 ) most cases are about the classical variant of occult PTC $(<1 \mathrm{~cm})$, the clinical significance of which is questionable $(4,5)$; 3 ) bilateral insult, multifocality and lymph node involvement are only rarely reported. To our knowledge, similar cases that have been reported in men are a case of multifocal PTC with cervical lymph node involvement (23) and a case of bilateral multifocal PTC (10). There are some relative data in two of the above mentioned large surgical series $(7,9)$, but the gender of patients was not specified in patients with extensive PTC.

There are not specific guidelines for the management of patients with concurrent PHPT and PTC; PTC in these patients is currently managed like cases of single PTC, according to recent guidelines (6). If thyroid nodular disease coexists in patients with PHPT apart from MEN syndromes, NMTC should also be excluded. Ultrasonography of the thyroid might be considered in patients with PHPT simultaneously with parathyroid ultrasonography. Preoperative thyroid fineneedle biopsy and intraoperative exploration should also be considered, before thyroidectomy is performed together with parathyroidectomy, in order to avoid un- necessary thyroidectomy or determine the extent and radicalness of the surgery. Especially in men, a more aggressive management should be considered, since they may carry a higher risk of malignancy, as in the cases of single thyroid nodular disease (24).

In conclusion, the cases with PHPT and incidental bilateral, multifocal, metastatic PTC are rare, especially in men. Ultrasonography of both thyroid and parathyroid glands might be considered in patients with PHPT. In case of concurrent PHPT and PTC, the patient should be managed like the cases of single PTC, according to recent guidelines (6).

Disclosure: no potential conflict of interest relevant to this article was reported.

\section{REFERENCES}

1. Fraser WD. Hyperparathyroidism. Lancet. 2009;374(9684):145-58.

2. Bilezikian JP, Khan AA, Potts JT Jr. Guidelines for the management of asymptomatic primary hyperparathyroidism: summary statement from the third international workshop. J Clin Endocrinol Metab. 2009;94(2):335-9.

3. Polyzos SA, Kita M, Avramidis A. Thyroid nodules - Stepwise diagnosis and management. Hormones (Athens). 2007;6(2):101-19.

4. Alevizaki M, Papageorgiou G, Rentziou G, Saltiki K, Marafelia P, Loukari $E$, et al. Increasing prevalence of papillary thyroid carcinoma in recent years in Greece: the majority are incidental. Thyroid. 2009;19(7):749-54.

5. Davies L, Welch HG. Increasing incidence of thyroid cancer in the United States, 1973-2002. JAMA. 2006;295(18):2164-7.

6. Cooper DS, Doherty GM, Haugen BR, Kloos RT, Lee SL, Mandel SJ, et al. Revised American Thyroid Association management guidelines for patients with thyroid nodules and differentiated thyroid cancer. Thyroid. 2009;19(11):1167-214.

7. Burmeister LA, Sandberg M, Carty SE, Watson CG. Thyroid carcinoma found at parathyroidectomy: association with primary, secondary, and tertiary hyperparathyroidism. Cancer. 1997;79(8):1611-6.

8. Cinamon U,Turcotte RE. Primary hyperparathyroidism and malignancy: "studies by nature". Bone. 2006;39(2):420-3.

9. Linos DA, van Heerden JA, Edis AJ. Primary hyperparathyroidism and nonmedullary thyroid cancer. Am J Surg. 1982;143(3):301-3.

10. Krause UC, Friedrich JH, Olbricht T, Metz K. Association of primary hyperparathyroidism and non-medullary thyroid cancer. Eur $\mathrm{J}$ Surg. 1996;162(9):685-9.

11. Nishiyama RH, Farhi D, Thompson NW. Radiation exposure and the simultaneous occurrence of primary hyperparathyroidism and thyroid nodules. Surg Clin North Am. 1979;59(1):65-75.

12. Bentrem DJ, Angelos $P$, Talamonti MS, Nayar R. Is preoperative investigation of the thyroid justified in patients undergoing parathyroidectomy for hyperparathyroidism? Thyroid. 2002;12(12):1109-12.

13. Attie JN, Vardhan R. Association of hyperparathyroidism with nonmedullary thyroid carcinoma: review of 31 cases. Head Neck. 1993;15(1):20-3.

14. Gul K, Ozdemir D, Korukluoglu B, Ersoy PE, Aydin R, Ugras SN, et al. Preoperative and postoperative evaluation of thyroid disease 
in patients undergoing surgical treatment of primary hyperparathyroidism. Endocr Pract. 2010;16(1):7-13.

15. Ogawa T, Kammori M, Tsuji E, Kanauchi H, Kurabayashi R, Terada K, et al. Preoperative evaluation of thyroid pathology in patients with primary hyperparathyroidism. Thyroid. 2007;17(1):59-62.

16. Lang W, Borrusch H, Bauer L. Occult carcinomas of the thyroid. Evaluation of 1,020 sequential autopsies. Am J Clin Pathol. 1988;90(1):72-6.

17. Martinez-Tello FJ, Martinez-Cabruja R, Fernandez-Martin J, LassoOria C, Ballestin-Carcavilla C. Occult carcinoma of the thyroid. A systematic autopsy study from Spain of two series performed with two different methods. Cancer. 1993;71(12):4022-9.

18. Lee JK, Obrzut SL, Yi ES, Deftos LJ, Bouvet M. Incidental finding of metastatic papillary thyroid carcinoma in a patient with primary hyperparathyroidism. Endocr Pract. 2007;13(4):380-3.

19. LiVolsi VA, LoGerfo P, Feind CR. Coexistent parathyroid adenomas and thyroid carcinoma. Can radiation be blamed? Arch Surg. $1978 ; 113(3): 285-6$
20. Meshikhes AW, Butt SA, Al-Saihati BA. Combined parathyroid adenoma and an occult papillary carcinoma. Saudi Med J. 2004;25(11):1707-10.

21. SatoY, Sakurai A, MiyamotoT, Hiramatsu K, Katai M, Furihata K, et al. Hyperfunctioning thyroid adenoma concomitant with papillary thyroid carcinoma, follicular thyroid adenoma and primary hyperparathyroidism. Endocr J. 1998;45(1):61-7.

22. Iakovou IP, Konstantinidis IE, Chrisoulidou AI, Doumas AS. Synchronous parathyroid adenoma and thyroid papillary carcinoma: a case report. Cases J. 2009;2:9121.

23. Kairaluoma MI, Heikkinen E, Mokka R, Huttunen R, LarmiTK. Nonmedullary thyroid carcinoma in patients with parathyroid adenoma. Acta Chir Scand. 1976;142(6):447-9.

24. Polyzos SA, Kita M, Efstathiadou Z, Goulis DG, Benos A, Flaris N, et al. The use of demographic, ultrasonographic and scintigraphic data in the diagnostic approach of thyroid nodules. Exp Clin Endocrinol Diabetes. 2009;117(4):159-64. 